\title{
Evaluation of water quality of Ramna and Gulshan lakes
}

\author{
Nusrat Rezwana Binte Razzak ${ }^{1}$, Abu Zafer Siddik ${ }^{1}$, Mohammad Ahmeduzzaman ${ }^{2}$ \\ ${ }^{1}$ Department of Civil \& Environmental Engineering, Bangladesh University of Engineering \& Technology, Dhaka, Bangladesh \\ ${ }^{2}$ Department of Civil Engineering, University of Manitoba, Canada
}

Email address:

tithi_stu@yahoo.com(N. R. B. Razzak), zafersiddik@gmail.com(A. Z. Siddik)

\section{To cite this article:}

Nusrat Rezwana Binte Razzak, Abu Zafer Siddik, Mohammad Ahmeduzzaman. Evaluation of Water Quality of Ramna and Gulshan Lakes. International Journal of Environmental Monitoring and Analysis. Vol. 1, No. 6, 2013, pp. 273-278.

doi: 10.11648/j.ijema.20130106.11

\begin{abstract}
Gulshan and Ramna Lake, prime green spots of Dhaka city are on the verge of extinction now. The objective of study was to evaluate the variation in water quality parameters in two distinct seasons. Water samples were collected along different points and analyzed for various physiochemical parameters during spring and winter. To explore the sources and reasons of pollution, the whole area in and around the lake was preliminarily surveyed. $\mathrm{pH}$ of all the samples of Gulshan and Ramna lake was within the ECR standard in both spring and winter. Gulshan lake samples were found more turbid and colored in spring than winter. Iron in water samples was within the range where 5 day BOD was found higher in both lakes. As Dhaka city is expanding day by day with the increasing rate of population, nowadays it has become a regular event that lake areas are used up by the land grabbers. As a result, the lakes are becoming narrower day by day. Wetlands of Dhaka city has been squeezed so that the pollution has become a great threat for the existence of aquatic lives. Poor lake water quality impacts the ecosystem and aesthetic features negatively.
\end{abstract}

Keywords: Eutrophication, Water Quality Parameters, Lake Water Pollution, Gulshan Lake, Ramna Lake

\section{Introduction}

Dhaka is located in the geographic center of the country. It is in the great deltaic region of the Ganges and Brahmaputra rivers. The city is within the monsoon climate zone, with an annual average temperature of $25 \mathrm{deg}$ c (77 $\operatorname{deg}$ F) monthly means varying between $18 \operatorname{deg} \mathrm{C}(64 \mathrm{deg} \mathrm{F})$ in August. Nearly $80 \%$ of the annual average rainfall of 1854 mm (73 in) occurs between May and September. Lake is smaller than canal or river. In a city lake is thought to be the store house of drain water, though some lakes may be kept free from the connection with drains. Lake water plays an important role to serve as many purposes like irrigation, aquaculture and livestock usage. Water quality is deteriorated day by day due to numerous biological, physical and chemical variables causing water toxicity. When concentration of any element or compound exceeds the tolerance limit for organisms that element is treated as pollutants. Research work has been carried out to determine some vital water quality parameters those abate the water quality and find out the most vulnerable location of both Gulshan and Ramna Lake.

Dhaka city is expanding day by day with the increasing rate of population; nowadays it has become a regular event that Lake Area is used up by the land grabbers. As a result all the main lake in Dhaka city is becoming narrow day by day. The Gulshan-Ramna Lake, one of the largest water bodies of the capital, is dying now. Lakes are no longer attractive to the eye and reduced to almost a drain. Conservation of water bodies is a major issue all over the world. Rapid urbanization together with encroachment, leading to the loss of catchments of surface water bodies and problems of siltation, pollution, which includes domestic, industrial and agricultural waste including eutrophication are the major problems of the world to protect and control water resources. (Jagdish Singh, 2012)

\section{Study Area}

\subsection{Gulshan Lake}

Gulshan Lake is the northernmost lake in a chain of water bodies (Gulshan Lake, Hatirjheel, Begunbari Khal, Balu River and Shitalakhya River) in Dhaka, suffering from highly significant pollution. Gulshan lake is located $23^{\circ} 48^{\prime}$ $\mathrm{N}$ and $90^{\circ} 25^{\prime} \mathrm{E}$ of Dhaka city. The length of the lake is 3.8 $\mathrm{km}$ which covers an area of $0.0160 \mathrm{~km}^{2}$. It has an average depth $2.5 \mathrm{~m}$ and volume $12 \times 105 \mathrm{~m}^{3}$ (Nishat A, 2000). The 
lake is a channel-like elongated water body. The peripheral sides are, northern at Baridhara, southern at TejgaonHatirjheel, western at Gulsan-Banani and eastern at Badda area. Gulshan-Baridhara Lake was declared an Ecologically Critical Area (ECA) in 2001 to save the water body from becoming further polluted and to protect it from encroachment (F. A. Mohuya, 2010). The lake has inlets through which it is connected with some old river channel and is, therefore, affected by flood water during peak flooding seasons. Many drains and gullies discharge into the lake. Previous study revealed that among the heavy metals only $\mathrm{Pb}$ concentration exceeded the standard level during the monsoon, otherwise concentrations of all other four heavy metals $(\mathrm{Cd}, \mathrm{Cr}, \mathrm{Cu}$ and $\mathrm{Ni})$ exceeded the standard level of drinking, fishing and surface water as set up by WHO, GOB, USEPA, DOE and FWPCA, for the summer period

\subsection{Ramna Lake}

Ramna Lake is situated in Ramna thana and it is a part of the Ramna Park. The area of Ramna Park is $277209.64 \mathrm{~m}^{2}$. In 1949 Ramna Lake was made. Institute of Engineering (IEB) is in the south-east of Ramna Lake. Shishu Park is situated in the southwest. Maximum portion of the park is in the north-west part. The area of Ramna Lake is 8.76 acre. Its width varies from $9-94 \mathrm{~m}$ to some points and the lake is 812 m long. (Razzak, 2012).

\section{Methodology}

The methodology of the study is given bellow:

- The lake \& surrounding areas have been surveyed to realize the present situations explore the reasons of the problems \& pollutions of the lakes.

- To determine the suitable locations of water collection entire lake areas have been visited. Water samples have been collected such that the samples represent the characteristics of whole lake.

- With a view to finding out the water quality parameters water samples have been tested in the Environmental Engineering laboratory of Stamford University Bangladesh.

\subsection{Sampling Locations}

In order to characterize the water from the lake, water samples were collected from three different locations, as listed in tables 1 and 2. Water samples were collected in plastic containers with stopper from beneath the surface from different sampling points. Plastic containers of capacity greater than 2 liters were used for sampling, and 2 liters of each sample in each location was collected for the study. Figure 1 and Figure 2 shows sampling locations in Gulshan Lake \& Ramna lakes respectively.
Table 1. Locations of water sampling points of Gulshan Lake

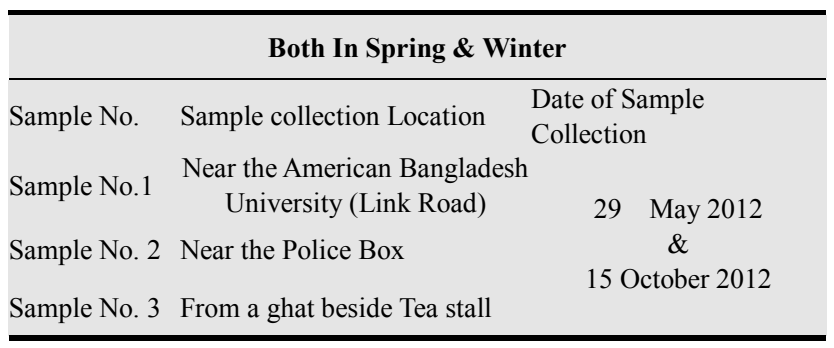

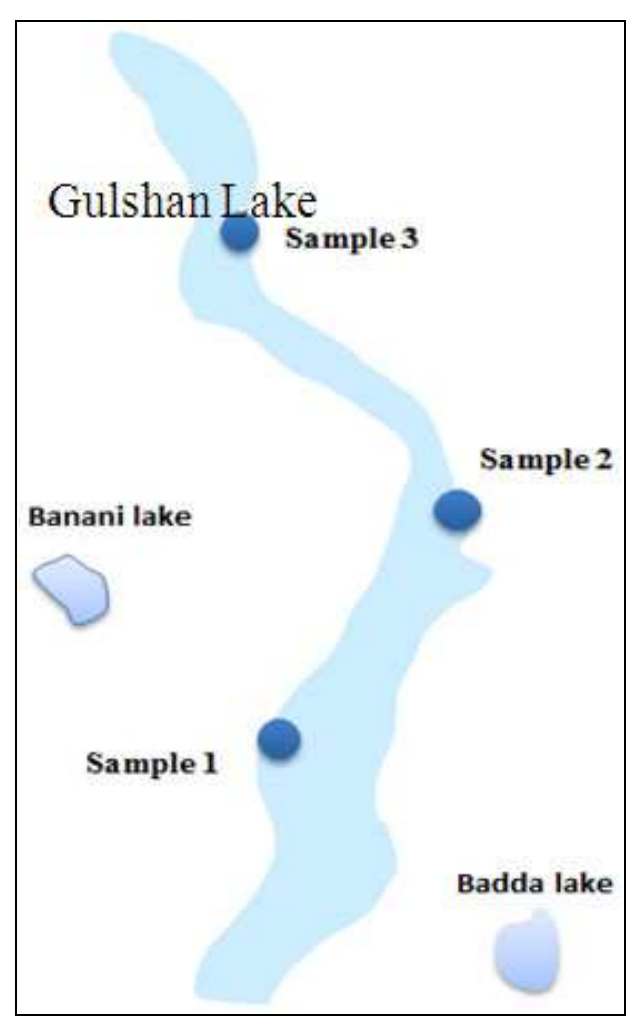

Figure 1. Sampling Locations of Gulshan Lake.

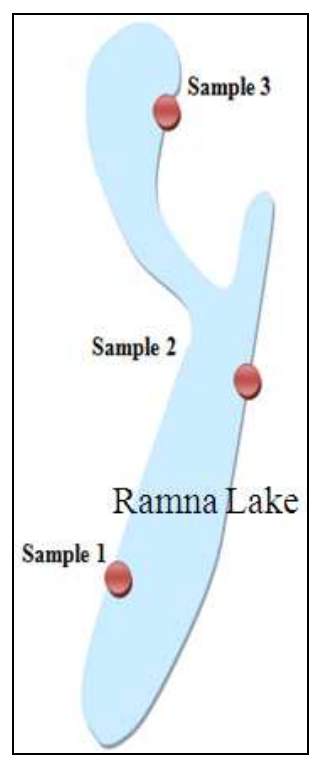

Figure 2. Sampling Locations of Gulshan Lake. 
Table 2. Locations of water sampling points of Ramna Lake

\begin{tabular}{llc}
\hline & \multicolumn{1}{c}{ Both In Spring \& Winter } \\
\hline Sample No. & Sample collection Location & Date of Sample Collection \\
Sample No.1 & From a ghat beside Chinese restaurant & 06 June 2012 \\
Sample No. 2 & About $120 \mathrm{~m}$ from the ghat & \& \\
Sample No. 3 & Another ghat about $370 \mathrm{~m}$ from $1^{\text {st }}$ ghat & October 2012 \\
\hline
\end{tabular}

\subsection{Laboratory Testing of the Samples}

Water quality parameters provide important information about the health of a water body. These parameters are used to find out if the quality of water is good enough for drinking water, recreation, irrigation, and aquatic life. Important parameters that are tested in the laboratory are given in table 3 .

Table 3. Tested parameters with standard values

\begin{tabular}{ll}
\hline Parameters & $\begin{array}{l}\text { Bangladesh Drinking water } \\
\text { Standard (Ahmed, 2000) }\end{array}$ \\
\hline $\mathrm{pH}$ & $6.5-8.5$ \\
$\mathrm{CO}_{2}, \mathrm{mg} / \mathrm{l}$ & $150-600$ \\
Turbidity, NTU & 15 \\
Color, pt-co & 10 \\
Iron, mg/l & $0.3-1.0$ \\
Biochemical Oxygen Demand, $\mathrm{mg} / 1$ & 0.2 \\
\hline
\end{tabular}

All the samples were directly carried to the laboratory. To minimize the time lag parameters were analyzed immediately by method given in APHA (1996) standard methods. Digital pH meter was used for the determination of $\mathrm{pH}$ of the sample. Turbidity of water affects other water quality parameters such as color, when it is imparted by colloidal particles. It also promotes the microbial proliferation, thus affecting negatively the microbiological quality of water. It also affects the chemical quality of drinking water through the formation of complexes between the turbidity causing humic matter and heavy metals (WHO,

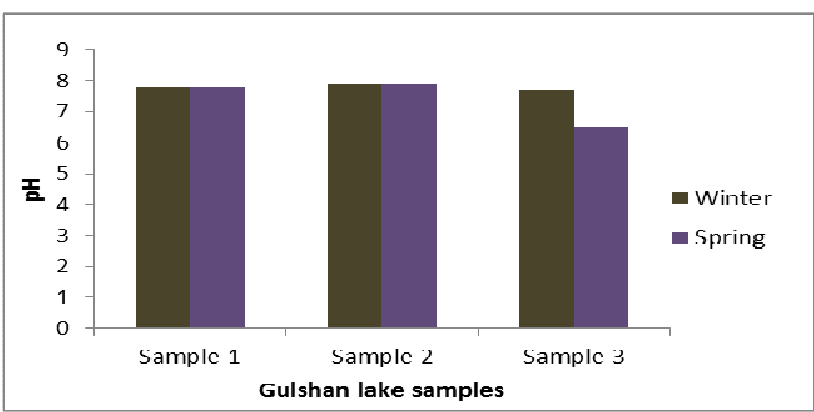

1984). Standardized HACH 2100 P turbidimeter was used for the turbidity test.

\section{Results and Discussions}

In this section the variation of different water quality parameters with respect to seasonal and spatial variation has been illustrated.

Dhaka has been experiencing huge migration and natural growth of population every year due to many push and pull factors. This huge population growth has increased the basic demand for settlements and utility services. These demands turn into establishment of both formal and informal settlements (slums and squatters) rapidly all around the city. Most of the parts of Gulshan are now more or less occupied due to both formal and informal settlements.

Physical pollutants to lakes and streams include materials such as particles of soil that are eroded from the landscape or washed from paved areas by flowing water. Point sources are also to be found to add wastewater into lake. The lake's biodiversity adds to its scenic beauty. But, rampant pollution is now completely changing its scenario as industrial waste from Tejgaon area is being dumped into the Gulshan Lake every day. The Gulshan Lake situated in the hub of diplomatic zone; industrial wastages as well as sewerage lines often fall in the lake resulting in bad odor and serious pollution of water. Blackish water was seen flowing in the lake. Gulshan Lake has also become a dumping ground for domestic wastes. Household wastes can cause acidification as there is a natural process of pollution. Many points of Gulshan are found to be covered with weeds which lead to acidification of lakes. Encroachment on Gulshan Lake has become a common practice now

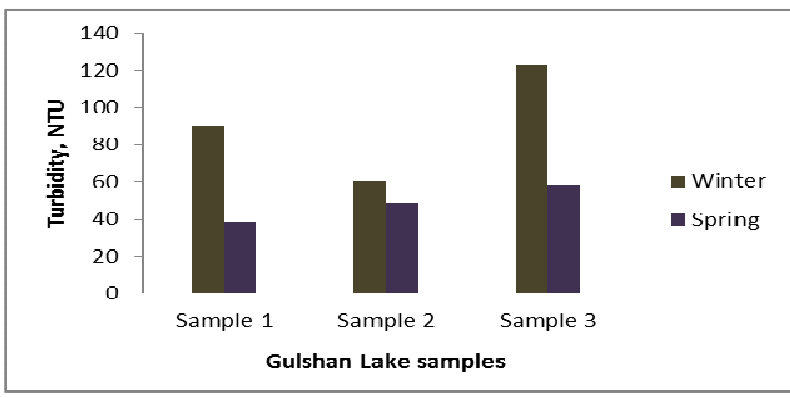



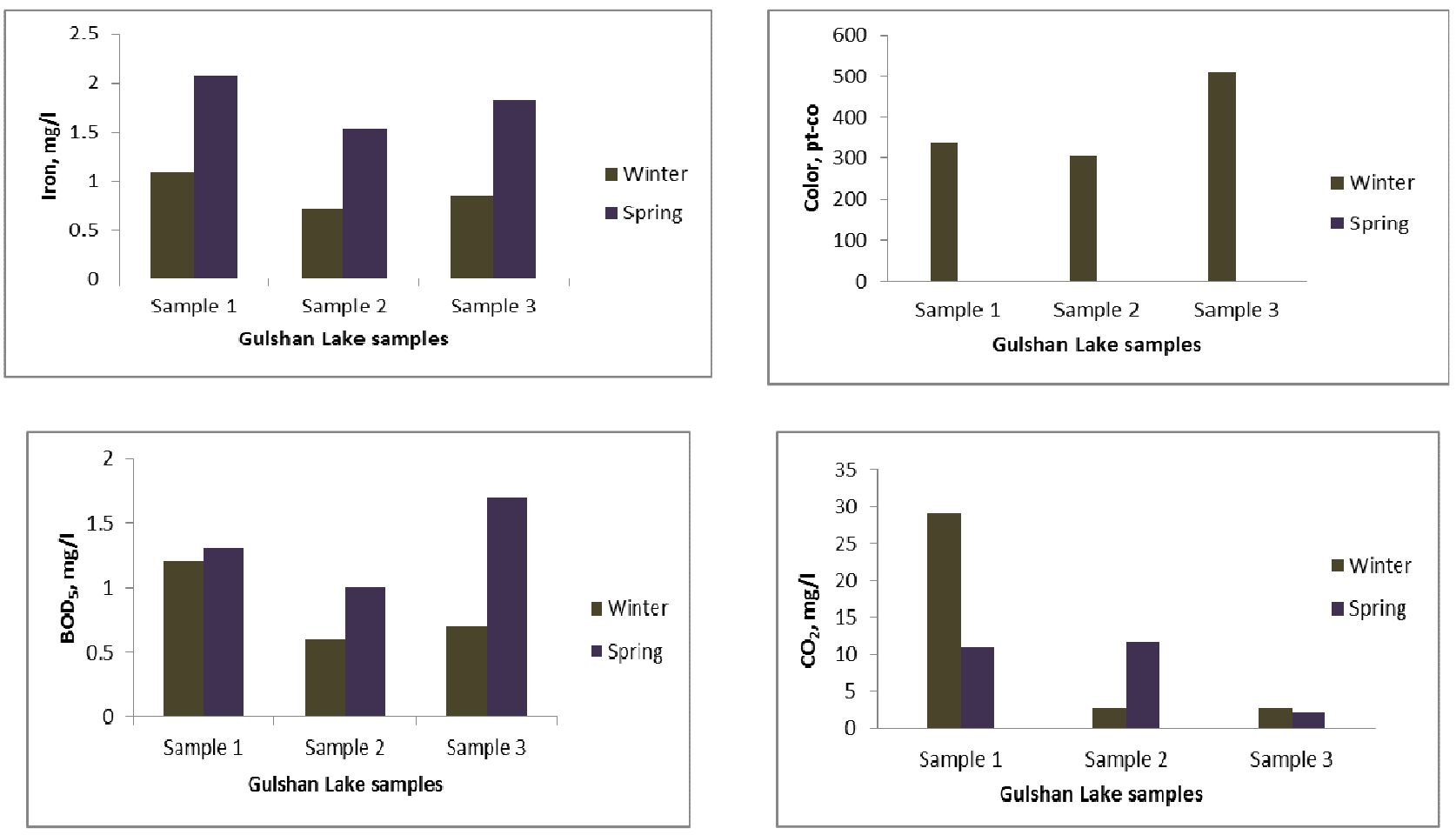

Figure 3. Seasonal variation of Water quality parameters in Gulshan Lake.

Figure 3 shows the seasonal variation of six water quality parameters in three different locations in Gulshan Lake. In this figure, $\mathrm{pH}$ of Gulshan Lake in both season are almost equal but the water of Gulshan Lake are more turbid and colorful in winter season compare with spring season. But,
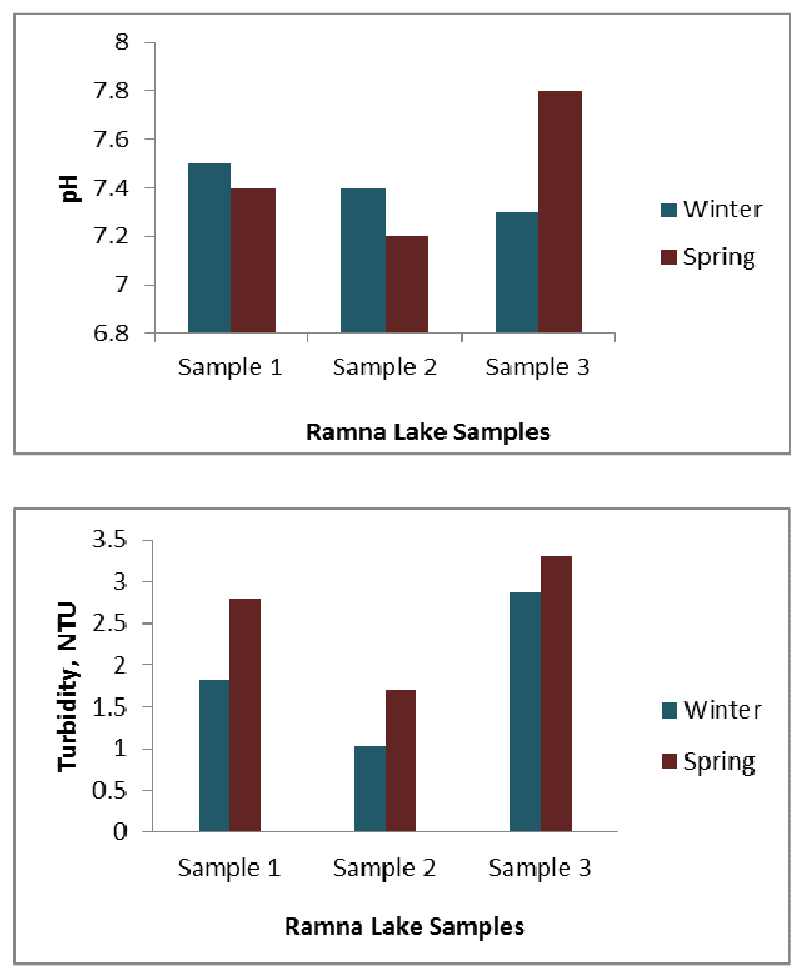

the situation is totally reverse in iron and BOD. $\mathrm{CO}_{2}$ of this water is quite high in sample 1 location and it decreases rapidly in the north direction of this lake. All the samples of Gulshan have iron level greater than the standard mentioned in ECR 1997.
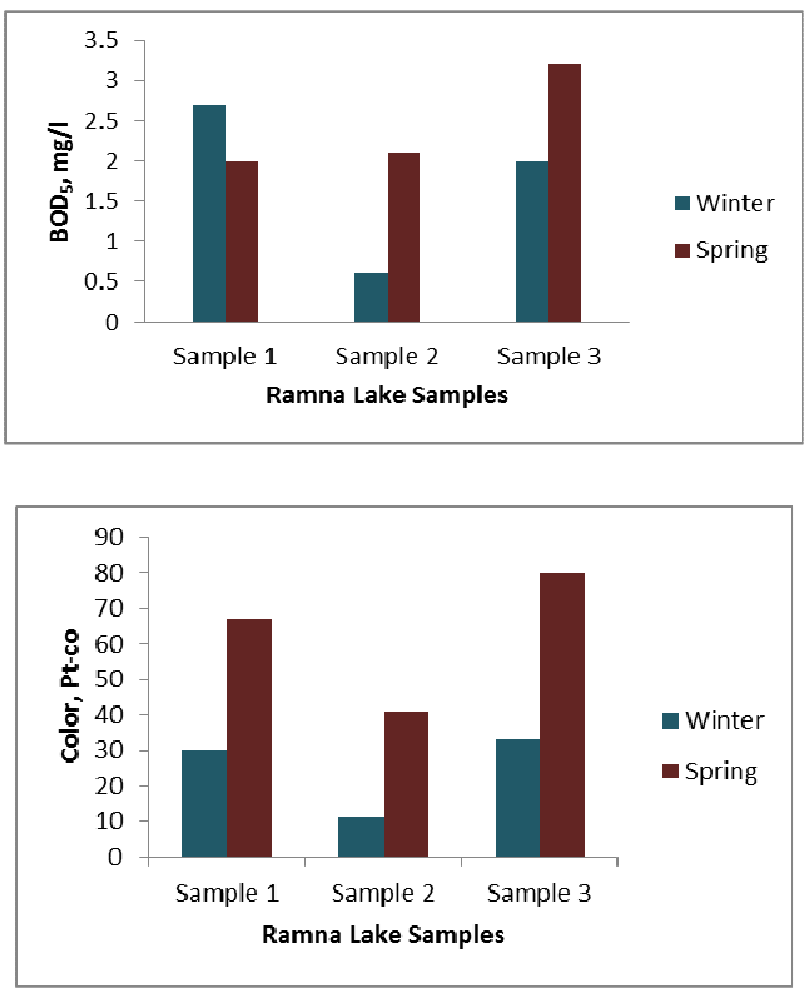

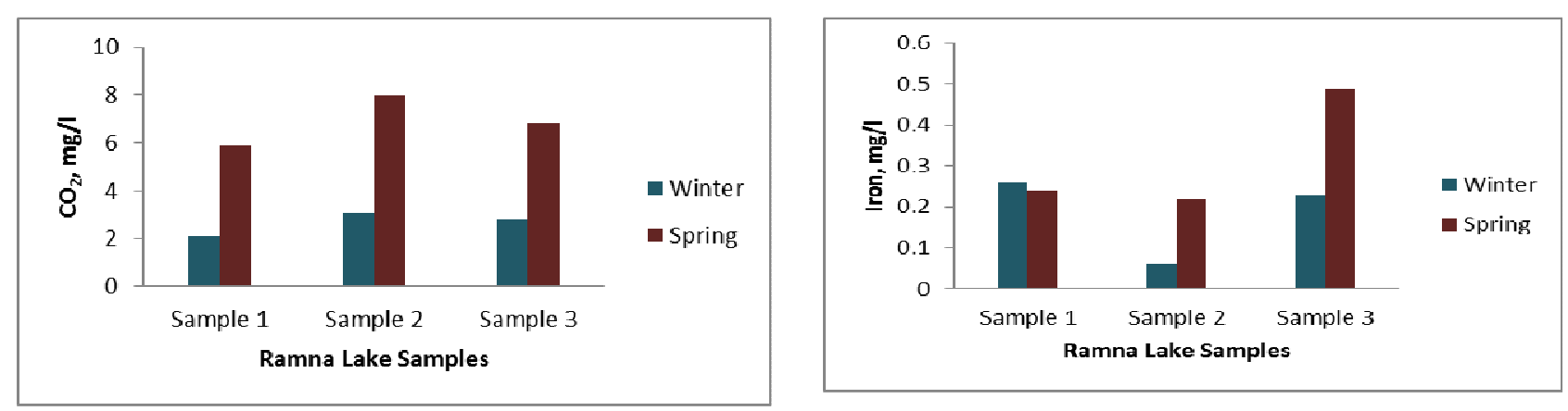

Figure 4. Seasonal variation of Water quality parameters in Ramna Lake.

Figure 4 represents variation of water quality parameter in Ramna Lake. It defines; all parameters are quite higher in spring period than winter season. BOD concentrations of all the samples exceeded the drinking water quality standards by GOB. Sample 3 location is most vulnerable location in both seasons among the others. Pollutant sources on both lakes are as follows:

- Discharge of treated or untreated municipal sewage and Storm runoff.

- Runoff and erosion from cultivation

- Runoff from streets, lawns and construction lots leads to nitrates and phosphates.

- Discharge of detergents which add phosphates leads to algal bloom.

- Nitrogen compounds produced by vehicles.

\section{Conclusions and Recommendations}

In Dhaka City, due to unplanned and excessive growth of urbanization and industrialization, lake water utilization and quality deterioration has been increased fast with the contribution to serious environmental degradation. Urban and agricultural runoff, industrial and municipal wastes are principal offenders. Generally this damage is measured in terms of interference with various uses of aquatic environment and the consequence reflected in the availability of safe water which became limited to most of the people. The water of the Gulshan Lake is severely polluted compared to the Ramna Lake. Sewage from the Badda, Baridhara, Gulshan and Banani residential areas along with toxic discharges from the nearby industries have contaminated the water of Gulshan Lake. A seasonal variation of lake water chemistry, due to pollution \& water level affects its biodiversity (flora, fauna) and ecological stability. Ground water chemistry also varies with this.

In this study period and study sample size was limited for test due to time limitation and was not enough to make total environmental study of the lakes. From the results of the laboratory tests it can be clearly stated that the concentrations of studied pollutants were higher during the spring. But during the winter the values were in general low and fall within various standard levels as water level increases.
Regarding authorities can take some initiative to save these prime green spots:

$\checkmark$ Preventing environmental threats before they turn into actual problems.

$\checkmark$ Updating phosphorus targets for open waters and near shore areas of each lake and taking actions to reduce phosphorus levels that contribute to harmful algae.

$\checkmark$ Preventing the introduction and spread of invasive species.

$\checkmark$ Developing plans to protect and restore near shore areas, where most cultural activities and recreation occurs.

$\checkmark$ Reaffirming actions necessary to restore and delist Areas of Concern.

$\checkmark$ Identifying new toxic substances, and implementing pollution prevention and control strategies.

$\checkmark$ Preventing and controlling harmful discharges.

$\checkmark$ Developing conservation strategies to protect native species and restore habitat.

$\checkmark$ Developing water quality and ecosystem health objectives.

$\checkmark$ Reporting progress to the public regularly.

Through a combination of government intervention and increased awareness of the importance and fragility of freshwater resources, pollution can be effectively managed in the future.

\section{References}

[1] J. Singh, "Water Conservation Methods to Overcome Scarcity, Pollution and Contamination of Water Resources, India", International Conference on Chemical, Ecology and Environmental Sciences (ICEES'2012), Bangkok, march $17-18,201$

[2] Nishat A, M Reazuddin, R Amin and AR Khan (eds.) 2000. "An Assessment of Environmental Impacts of Flood 1998 on Dhaka City", Department of Environment and International Union for Conservation of Nature, Dhaka. In: Dhaka City State of Environment, 2005.

[3] F. A. Mohuya, R. H. Bhuiyan and S. Hoque "Heavy metal contamination in Gulshan-Baridhara lake, Dhaka", Dhaka Univ. J. Biol. Sci. 19(1): 53-61, January 2010.

[4] WHO (World Health Organization) 1972. Health Hazards of 
Human Environment. WHO. Jeneva. 1972

[5] GOB (Government of Bangladesh) 1997. Environment Conservation Regulation 1997. Government of People's Republic of Bangladesh, 1997.

[6] USEPA (United States Environmental Protection Agency) 2000. Drinking Water Quality Standards. United States Environmental Protection Agency. (http://www.epa.gov/safewater/contaminants/index.html)

[7] DOE (Department of Environment) 1991. Environmental Water Quality Standard for Bangladesh. Ministry of Environment and Forest, Government of the People's Republic of Bangladesh.

[8] FWPCA 1968. US Department of Interior Federation Water Pollution Control Administration, Washington, DC, USA. In:Bashar et al. 2007. Heavy Metals in the Water of Some Chittagong Region River Systems. J. Asiat. Soc. Bangladesh, Sci. 33(1): 57-68.
[9] N. R. B. Razzak, S. Y. Muntasir and S. Chowdhury, "Pollution scenario of Dhaka city Lakes: A case study of Dhanmondi and Ramna lakes". Global Engineers \& Technologists Review, Vol.2 No.7 July 2012.

[10] APHA (1996). Standard Methods for the Examination of Water and Wastewater.

[11] WHO (1984). Health criteria and other supporting information 101: 2

[12] M. F. Ahmed, M. Rahman, "Water Supply \& Sanitation-Rural and Low Income Urban Communities" ITN-Bangladesh, 338, June 2000. 